\title{
NONINVASIVE LARGE THYMOMA WITH A NATURAL HISTORY OF TWENTY-ONE YEARS
}

\author{
Iwao Takanami, MD, Ken Takeuchi, MD, and Masao Naruke, MD, Tokyo, Japan
}

Thymomas are slow-growing neoplasms that are considered to be malignant because of their potential invasiveness. Invasion beyond the capsule is a major prognostic factor that correlates with a poor outcome. Surgery is usually the therapy of choice in the management of thymomas. We report a case of thymoma that was seen as a large mediastinal tumor without invasiveness or dissemination and had been discovered by routine chest radiography 21 years earlier. Because there are no known previous reports of such a long-standing thymoma without treatment, we report this case.

Clinical summary. The patient was a 62-year-old Japanese man. In 1978, when the patient was 41 years old, a tumorous mass was discovered in the mediastinum by routine chest radiography. The patient had no symptoms and refused further examinations and medical care. Abnormal shadow was seen in the mediastinum on routine chest radiography yearly thereafter. The patient remained free of symptoms for 21 years from 1978 to 1999 , when he had appetite loss and fatigue. He was then admitted to our hospital.

The patient appeared critically ill and had lost $3 \mathrm{~kg}$ in weight during the previous 6 months. Physical examination revealed diminished breath sounds on the right side. Blood tests revealed nothing abnormal. Chest x-ray and chest computed tomographic examinations revealed a large tumor in the mediastinum, which severely compressed the right lung (Figs 1 and 2). A diagnosis of the thymoma with predominantly epithelial composition was made after examination of a cutaneous needle biopsy specimen.

From the Department of Surgery, Teikyo School of Medicine, Tokyo, Japan.

Received for publication July 14, 1999; accepted for publication July 27, 1999.

Address for reprints: Iwao Takanami, MD, Department of Surgery, Teikyo School of Medicine, 2-11 Kaga 2-Chome, Itabashi-Ku, Tokyo, 173 Japan.

J Thorac Cardiovasc Surg 1999;118:1134-5

Copyright (C) 1999 by Mosby, Inc.

0022-5223/99 $\$ 8.00+0 \quad \mathbf{1 2 / 5 4 / 1 0 1 7 3 7}$

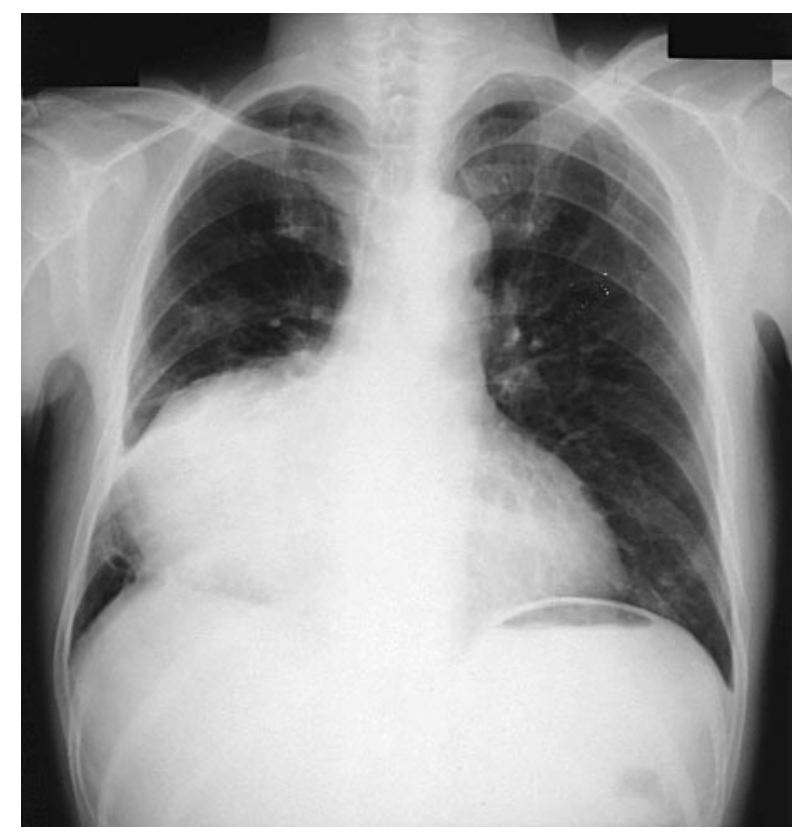

Fig 1. Preoperative chest $\mathrm{x}$-ray film demonstrates large mass lesion in right thorax.

Total resection of the tumor was accomplished through a median sternotomy with anterolateral thoracotomy. The tumor was shown to arise from the right lobe of the thymus and was slightly inflammatory and adherent to the surrounding structures but was not invasive of the pleura and the pericardium. The tumor was exclusively resected with intraoperative blood loss of $836 \mathrm{~mL}$. The tumor measured $13 \times 10 \times$ $10 \mathrm{~cm}$ and weighed $670 \mathrm{~g}$. Histologic examination revealed it to be an encapsulated epithelial thymoma at stage 1 according to Masaoka and colleagues' classification. ${ }^{1}$ After the operation the patient did well, and he remained free of disease 3 months after the operation. 


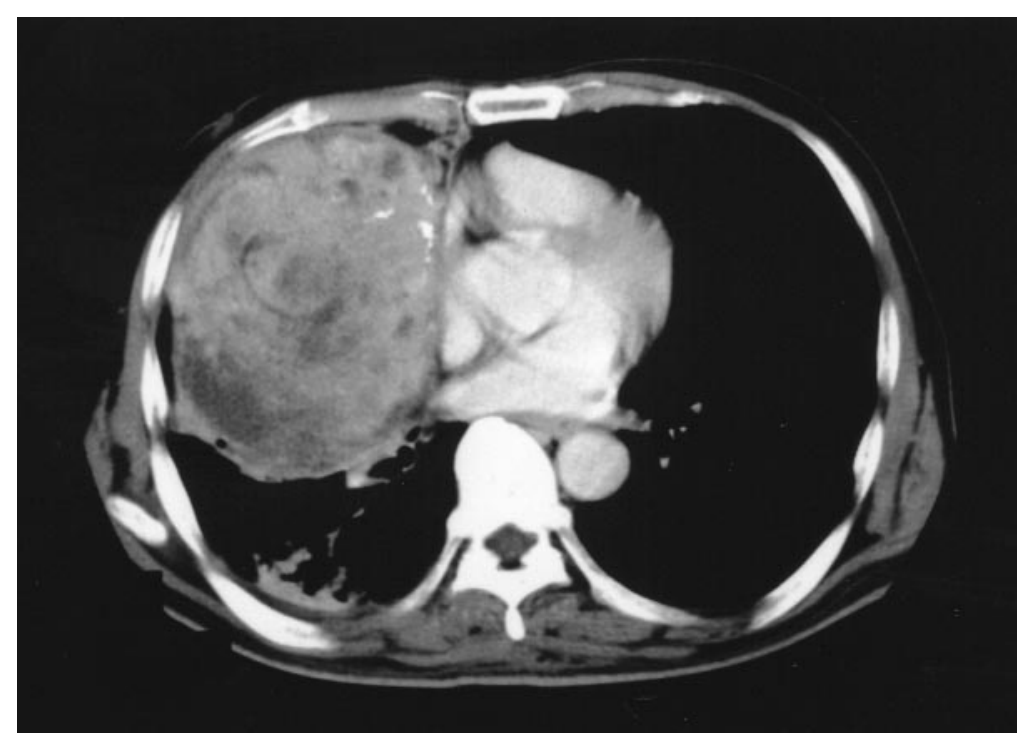

Fig 2. Chest computed tomographic scan reveals large tumor compressing right lung.

Discussion. Thymoma is the most common tumor of the anterosuperior mediastinum. In a long series of 283 patients with thymoma from the Mayo Clinic, ${ }^{2}$ chest pain was the most common initial symptom $(25 \%)$ and $40 \%$ of patients were first seen with tumor-related symptoms. Sixty percent of these patients were free of symptoms. The patient whose case is presented here had been free of symptoms for 21 years since the mass was discovered by routine chest radiography. The lack of respiratory symptoms in this patient was not surprising. There have been some reports of incidental detection of thymoma during routine cardiac examination. Large numbers of occult thymomas may be present in the symptom-free population. Thymomas show a great variation in size, with most ${ }^{2}$ between 5 and $10 \mathrm{~cm}$. The largest thymoma recorded in the literature ${ }^{3}$ had a dimension of $34 \times 28 \times 26 \mathrm{~cm}$ and weighed $5700 \mathrm{~g}$, and there was also a report of a huge thymoma that was discovered to be causing dyspnea, although it remained noninvasive. ${ }^{4}$ Our patient's tumor measured $13 \times$ $10 \times 10 \mathrm{~cm}$ when it was removed.

To our knowledge there are no previous reports of such a long-standing thymoma without specific treatment. The most widely used staging system is that of Masaoka and associates, ${ }^{1}$ which takes into account the extent of clinical and histologically determined disease involvement. This staging system suggests a biologic continuum from noninvasive thymoma to invasive thymoma, followed by lymphogenous or hematogenous metastatic thymoma. Noninvasive thymo- mas carry a low relapse rate, and an extensive review ${ }^{5}$ reported an $80 \%$ average survival for patients with noninvasive thymomas, compared with less than $50 \%$ for those with invasive tumors. A reasonable assumption is that an invasive thymoma originates as a noninvasive thymoma and that a noninvasive thymoma will progress to invasive thymoma and ultimately to metastatic thymoma. Although our patient's tumor was present for 21 years, however, it remained noninvasive. This case illustrates that the aforementioned assumption does not necessarily mean that all thymomas will eventually progress to become invasive.

\section{REFERENCES}

1. Masaoka A, Monden Y, Nakahara K, Tanioka T. Follow-up study of thymomas with special reference to the clinical stages. Cancer 1981;48:2485-92.

2. Lewis JE, Wick MR, Scheithaneuer BW, Bernatz PE, Taylor WF. Thymoma: a clinicopathologic review. Cancer 1987;60:2727-43.

3. Smith WF, DeWall RA, Krumholy RA. Giant thymoma. Chest 1970;58:383-5.

4. Tsubota N, Muratani A, Yoshimura M. A huge non-invasive thymoma causing acute dyspnea. Tohoku J Exp Med 1993;171:229-33.

5. Mornex F, Rosbeut M, Richaud P, Jung GM, Mirabel X, Marchal $\mathrm{C}$, et al. Radiotherapy and chemotherapy for invasive thymomas: a multicentric retrospective review of 90 cases. The FNCLCC trialists. Fédération Nationale des Centres de Lutte Contre le Cancer [published erratum appears in Int J Radiat Oncol Biol Phys 1995;33:545]. Int J Radiat Oncol Biol Phys 1995;32:651-9. 